\title{
Ablation of Neurons Expressing Agouti-Related Protein Activates Fos and Gliosis in Postsynaptic Target Regions
}

\author{
Qi Wu, ${ }^{1,2}$ Maureen P. Howell, ${ }^{3}$ and Richard D. Palmiter ${ }^{1,2}$ \\ ${ }^{1}$ Howard Hughes Medical Institute, ${ }^{2}$ Department of Biochemistry, University of Washington, Seattle, Washington 98195, and ${ }^{3}$ Allen Institute for Brain \\ Science, Seattle, Washington 98103
}

We have developed a mouse model in which a specific population of inhibitory neurons can be selectively ablated by the action of diphtheria toxin (DT). The model involves targeting the human DT receptor to the agouti-related protein (Agrp) locus so that systemic administration of DT kills all of the AgRP-expressing neurons, resulting in starvation of the mice. Ablation of AgRP neurons results in robust (5- to 10-fold) activation of Fos gene expression in many brain regions that are innervated by AgRP neurons, including the arcuate nucleus (ARC), the paraventricular nucleus, the medial preoptic area, the lateral septum, and nucleus of the solitary tract. As expected, there is robust increase in GFAP staining (astrocytes) as well as IBA1 and CD11b staining (microglia) in the ARC in response to AgRP neuron ablation. There is also a dramatic increase of these markers in most, but not all, postsynaptic targets of AgRP axons. We used a genetic approach to reduce melanocortin signaling, which attenuated Fos activation in some brain regions after ablation of AgRP neurons. We suggest that loss of inhibitory signaling onto target neurons results in unopposed excitation that is responsible for the activation of Fos and that dysregulation of these neuronal circuits is responsible for starvation. Furthermore, glial cell activation in target areas of AgRP neurons appears to be a result of excitotoxicity.

Key words: neuronal death; feeding; glia; hypothalamus; appetite; network; hindbrain

\section{Introduction}

Neuronal death occurs as a natural process during development and as a consequence of traumatic events in the mature nervous system. The detection, removal, and shielding of dying neurons is an integrated process that involves participation by astrocytes and microglia as they attempt to preserve the functional integrity of the remaining viable components. Analysis of signaling events between neurons and glial cells that mediate the smooth transition from cell death to reorganization of remaining components is just beginning to be understood (Fields and Stevens-Graham, 2002; Hara and Snyder, 2007).

We have developed a method to kill a specific neuronal population in the adult mouse in a relatively rapid and reproducible manner. We targeted expression of diphtheria toxin receptor (DTR) to neurons that express AgRP and then administered diphtheria toxin (DT) to adult mice, which resulted in ablation of the neurons over the next few days and starvation by $\sim 6 \mathrm{~d}$ ( Luquet et al., 2005). This method of ablation is specific for AgRPexpressing cells, conditional on DT administration, convenient in that DT can be administered by any route, and reproducible (Luquet et al., 2005).

Received May 30, 2008; revised July 22, 2008; accepted July 31, 2008.

This work was supported in part by National Institutes of Health Grant DA024908 (to R.D.P). We thank Glenda Froelick and Betty Li for help with histology, Aundrea Rainwater for help with mouse breeding, and the staff of the Allen Brain Research Institute for performing the in situ hybridization studies. We appreciate the helpful comments on this manuscript by Drs. Nephi Stella and Tomas Möller.

Correspondence should be addressed to Richard D. Palmiter at the above address. E-mail: palmiter@u.washington.edu.

DOI:10.1523/JNEUROSCI.2449-08.2008

Copyright $\odot 2008$ Society for Neuroscience $\quad$ 0270-6474/08/289218-09\$15.00/0
AgRP neurons are part of a hypothalamic regulatory system that detects and integrates various nutritional, hormonal, and neuronal signals to regulate appetite and metabolism and thereby help maintain energy balance (Broberger et al., 1998). AgRP neurons and the neighboring pro-opiomelanocortin (POMC)expressing neurons send their axonal projections to the same brain regions. The POMC neurons produce melanocortin [ $\alpha$-melanocyte-stimulating hormone $(\alpha$-MSH $)]$, which activates melanocortin 4 receptors (MC4Rs) on postsynaptic cells (Cone, 2005). Activation of this melanocortin pathway inhibits feeding and stimulates metabolism. The AgRP neurons counteract the actions of melanocortin signaling by directly inhibiting POMC neurons via GABA release (Cowley et al., 2001), and counteracting the action of melanocortin on postsynaptic cells: AgRP antagonizes binding of melanocortin to MC4R (Cone, 2005), NPY activates $\mathrm{G}_{\alpha \mathrm{i}}$-coupled receptors (Marsh et al., 1998; Pedrazzini et al., 1998), and GABA activates $\mathrm{GABA}_{\mathrm{A}}$ receptors. Thus, AgRP neurons promote feeding, at least in part, by counteracting the actions of the melanocortin signaling. Consistent with this arrangement, ablation of AgRP neurons in adult mice leads to starvation (Gropp et al., 2005; Luquet et al., 2005, 2007; Phillips and Palmiter, 2008).

Here we describe cellular consequences of AgRP neuron ablation that help delineate why the mice starve. Death of AgRP neurons is associated with Fos gene activation, as well as robust gliosis, in the target areas. We suggest that dysregulation of postsynaptic cells is responsible for the failure of the mice to eat. We distinguish whether glial cell activation is caused by either axonal degeneration or excessive excitation. 


\section{Materials and Methods}

Animal maintenance and neuron ablation. Mice were housed in a temperature- and humidity-controlled facility with a $12 \mathrm{~h} \mathrm{light/dark}$ cycle. All animal care and experimental procedures were approved by the Institutional Animal Care and Use Committee at the University of Washington (Seattle, WA). Agrp ${ }^{D T R /+}$ mice were generated by targeting the human diphtheria toxin receptor (heparin-binding epidermal growth factor) to the Agrp locus (Luquet et al., 2005). $A^{y}$; $\operatorname{Agrp}^{D T R /+}$ mice were generated by mating homozygous Agrp ${ }^{D T R / D T R}$ with heterozygous lethal yellow $A^{y} / a$ mice obtained from The Jackson Laboratory. The yellow mice derived from this cross comprise the $A^{y} ; A g r p^{D T R /+}$ group, whereas the black littermates served as Agrp $p^{D T R /+}$ controls. Mice were group housed with standard chow diet (LabDiet 5053), and water was provided ad libitum until the beginning of the experiments. To ablate AgRP neurons in adult mice, intramuscular injection of diphtheria toxin (two injections of $50 \mu \mathrm{g} / \mathrm{kg}, 2 \mathrm{~d}$ apart; List Biological Laboratories) in 6-weekold mice was performed (Luquet et al., 2005).

In situ hybridization. Brains were sectioned (coronal; $25 \mu \mathrm{m}$ ), and every eighth section was used for either Nissl staining or in situ hybridization with Npy, Agrp, Fos, Egrl, or Arc using an automated procedure for hybridization and image capture. We present the results obtained with Fos in this study. The results obtained with Agrp were published previously (Wu et al., 2008); results obtained with Npy in the ARC were identical. The results obtained with Egrl were similar to those of Fos except that the differential response in the $a / a$ versus the $A^{y} / a$ genetic background was not apparent after DT injection. The Arc hybridization signals were weak in most regions of interest compared with Fos or Egr1. The hybridization data collected for Egrl and Arc are available on request. Materials and procedures concerning this high-throughput data generation process (riboprobe production, tissue processing, in situ hybridization, image capture, and processing) have been described previously (Lein et al., 2007) and are available on the Allen Brain Atlas website (http://www.brain-map.org).

Immunohistochemistry. Mice were killed by $\mathrm{CO}_{2}$ asphyxiation and perfused transcardially with ice-cold PBS buffer containing $4 \%$ paraformaldehyde. Brains were dissected and postfixed overnight at $4^{\circ} \mathrm{C}$ in the fixation buffer. Free-floating brain sections $(30 \mu \mathrm{m})$ were washed in PBS and $0.1 \%$ Triton X-100 (PBST buffer) solution three times for $15 \mathrm{~min}$ and then blocked with 3\% normal donkey serum in PBST for 2-3 h at room temperature. Rabbit anti-NPY (Peninsula Laboratories; 1:1000 dilution), rabbit anti-GFAP (Novus Biologicals; 1:3000 dilution), rabbit anti-IBA1 (Wako Chemicals; 1:1000 dilution), rabbit anti-Fos (Calbiochem; 1:6000 dilution), rat anti-CD11b (AbD Serotec; 1:1000 dilution), mouse anti-NeuN (Millipore Bioscience Research Reagents; 1:100 dilution), and/or mouse anti-ACTH (Santa Cruz Biotech; 1:100 dilution) were applied to the sections for overnight incubation at $4^{\circ} \mathrm{C}$, followed by three $15 \mathrm{~min}$ rinses in PBST. Finally, sections were incubated in (cyanine 2)- or $\mathrm{Cy} 3$ (indocarbocyanine)-labeled secondary antibody (Jackson ImmunoResearch; 1:500 dilution) before visualization. Images were captured using a digital camera mounted on a TCS SP1 confocal microscope (Leica); all paired photos were obtained through the same system setting. For each group of mice, at least eight sections from four different mice were analyzed.

Data analysis. Quantification of Fos-positive cells was done using the NIH Image software (National Institutes of Health). Anatomical correlations of brain sections and delineation of individual nuclei were determined by comparing landmarks of Nissl staining images with those given in the Paxinos stereotaxic atlas (Paxinos and Frank, 2001). From the anatomically matched sections, a region of interest of the same size was further defined. Meanwhile, an optimized threshold that can discern round Fos-positive nuclei from partially stained ones as well as background noise was preset for all measurement. The total number of pixels of Fos-positive cells inside the defined region was automatically recorded. The signal intensity of NPY and glial cell markers (GFAP, IBA1, and CD11b) was quantitatively assessed using the NIH Image software under the same exposure and threshold setting to quantify the variance of expression level. Data sets collected from all experiments, unless otherwise stated, were analyzed by one-way ANOVA followed by the Student-
Newman-Keuls method for statistical significance and plotted as means \pm SEM. Post hoc analysis was performed when group differences were significant by ANOVA at $p<0.05$.

\section{Results}

\section{Ablation of AgRP neurons by administration of DT induces} Fos and gliosis in the ARC

The generation of $A g r p^{D T R /+}$ mice with the cDNA encoding the human DTR targeted to the Agrp locus has been described previously (Luquet et al., 2005). Administration of DT ( 2 intramuscular injections at $50 \mu \mathrm{g} / \mathrm{kg}$ body weight, $2 \mathrm{~d}$ apart) results in reliable loss of appetite such that feeding virtually ceases and body weight falls by $20 \%$ by the sixth day (Fig. $1 \mathrm{~A}$ ) (Luquet et al., 2007; Phillips and Palmiter, 2008; Wu et al., 2008). We terminated the experiments at that point because of animal care concerns, but we know that the mice would die within another day or so. We showed previously that this DT treatment protocol results in the nearly complete loss of Agrp hybridization signal in the ARC by day 6 after initiation of DT treatment (Wu et al., 2008), in agreement with previous results using antibodies to either AgRP or NPY (Luquet et al., 2005, 2007).

DT treatment also leads to the activation of Fos and gliosis in various brain regions, including the ARC, on day 6 after initiation of DT treatment (Wu et al., 2008). To examine the kinetics of Fos activation and initiation of gliosis, the ARC region of the hypothalamus was examined by immunohistochemistry after treating Agrp ${ }^{D T R /+}$ mice with DT for 2, 4, or $6 \mathrm{~d}$. There was robust staining for Fos (half-maximal) within the first $2 \mathrm{~d}$ after initiating DT treatment, at a time when there was no apparent loss of NPY neurons (Fig. $1 B, D, E, P, Q$ ) and no inhibition of feeding (Fig. $1 A)$. In addition, microglial activation was readily apparent in the vicinity of NPY neurons as revealed by staining with an antibody to IBA1 (ionized calcium binding adapter molecule 1, a microglia marker; product of the Aif1 gene) (Fig. $\left.1 B, H, I, H^{\prime}, I^{\prime}\right)$. By day 4, when feeding began to be affected, there was a small loss of NPY staining in cell bodies within the ARC (Fig. $1 B, R$ ). Staining of Fos and IBA1 was maximal at day 4 , and CD11b (integrin $\alpha_{\mathrm{m}} \beta_{2}$, another marker of activated macrophages) staining became prominent (Fig. $1 B, F, J, J^{\prime}, L-N$ ). By day 6 , the mice consumed very little food and they had lost $\sim 20 \%$ of their body weight; NPY staining in the ARC was almost gone, but Fos and microglia staining persisted (Fig. $1 B, G, K, K^{\prime}, O, S$ ). Nissl staining revealed that there was $\sim 25 \%$ loss of neurons in the ARC at day 6 (Fig. 2). These data suggest that $2 \mathrm{~d}$ of DT treatment affects the function of AgRP neurons, leading to the activation of Fos in surrounding neurons. Microglia also start to become activated on day 2, several days before there is obvious loss of NPY/AgRP neurons or an overt effect on feeding behavior.

On day 6 after DT treatment, all POMC neurons were Fos positive, as predicted from the loss of inhibitory input from the AgRP neurons (Wu et al., 2008), but POMC neurons accounted for only $\sim 38 \%$ of the Fos-positive cells in the ARC (Fig. 3), indicating that other neuronal populations in the ARC also became activated. Meanwhile, virtually all of the Fos-positive cells $(>97 \%)$ were determined to be neurons, as revealed by NeuN, a neuron-specific cell marker (Fig. 3D).

\section{Activation of Fos expression and gliosis in the paraventricular nucleus after ablation of AgRP neurons}

The paraventricular nucleus (PVN) is a primary brain region that integrates opposing signals via projections from AgRP and POMC neurons (Balthasar et al., 2005; Kublaoui et al., 2006; Yang et al., 2006). We examined Fos and microglia markers in the 
PVN of the same mice that were used to study these markers in the ARC. None of these markers were significantly elevated relative to controls $2 \mathrm{~d}$ after DT treatment, but they were all increased $4 \mathrm{~d}$ after DT treatment and even more so at $6 \mathrm{~d}$ (Fig. $1 C)$. There was no loss of neurons in the PVN as assessed by Nissl staining (Fig. 2). Thus, activation of neurons and microglia in this projection field of AgRP neurons was delayed relative to that observed in the area surrounding the AgRP neuron cell bodies in the ARC.

\section{Induction of Fos and gliosis in the PVN is attenuated in the absence of $\boldsymbol{\alpha}$-MSH signaling}

We also examined mice in which the $A g r p^{D T R}$ allele was bred into the $A^{y}$ genetic background (designated $A^{y} ; \operatorname{Agr} p^{D T R /+}$ ) to examine the consequences of suppressed melanocortin signaling on Fos gene activation. The $A^{y}$ mice express agouti protein ectopically in virtually all tissues including the brain (Michaud et al., 1993). Like AgRP, agouti protein antagonizes the action of $\alpha-\mathrm{MSH}$ binding to MC4R and, thus, prevents melanocortin signaling via the $G_{\alpha s}$-coupled receptor on postsynaptic cells (Cone, 2005). We reasoned that because AgRP neurons innervate the same postsynaptic targets as POMC neurons, activation of Fos in those postsynaptic cells after ablation of inhibitory AgRP neurons would be reduced if melanocortin signaling was blocked.

A high-throughput protocol was used to allow quantitative comparison of in situ hybridization signals from three different genes (Fos, Npy, Agrp) in 160 sections from each of three to six brains from wild-type, $A g r p^{D T R /+}$, and $A^{y}$; Agrp ${ }^{D T R /+}$ mice that were either treated with DT or not (Lein et al., 2007). Over 1600 mouse brain sections were examined for this study.

We examined Fos induction in the PVN of AgRP neuron-ablated mice in both wild-type and $A^{y}$ genetic backgrounds. To detect Fos induction elicited by stress of starvation, control groups including DTtreated wild-type, naive $\operatorname{Agrp} p^{D T R /+}$ and naive $A^{y} ; \operatorname{Agrp}^{D T R /+}$ mice that were food restricted by pair feeding $(\mathrm{PF})$ to lose the same body weight as the neuron-ablated animals were used. A DTtreated group of wild-type mice was also included to identify DT-associated cellular stress responses.

Ablation of AgRP neurons by DT treatment of Agrp $p^{D T R /+}$ mice dramatically activated Fos expression in the PVN compared with two different PF control groups (Fig. $4 C, C^{\prime}$ compared with $A, A^{\prime}$ or $B, B^{\prime}$, images from two different mice; data from $\geq 4$ mice are quantified in Fig. $4 R$ ). There was no appreciable Fos signal in untreated wild-type (WT) mice (data not shown). Fos mRNA increased $>5$-fold in the PVN of DT-treated $\operatorname{Agrp}^{D T R /+}$ mice relative to the pair-fed or DT-treated, wild-type controls $(p<$
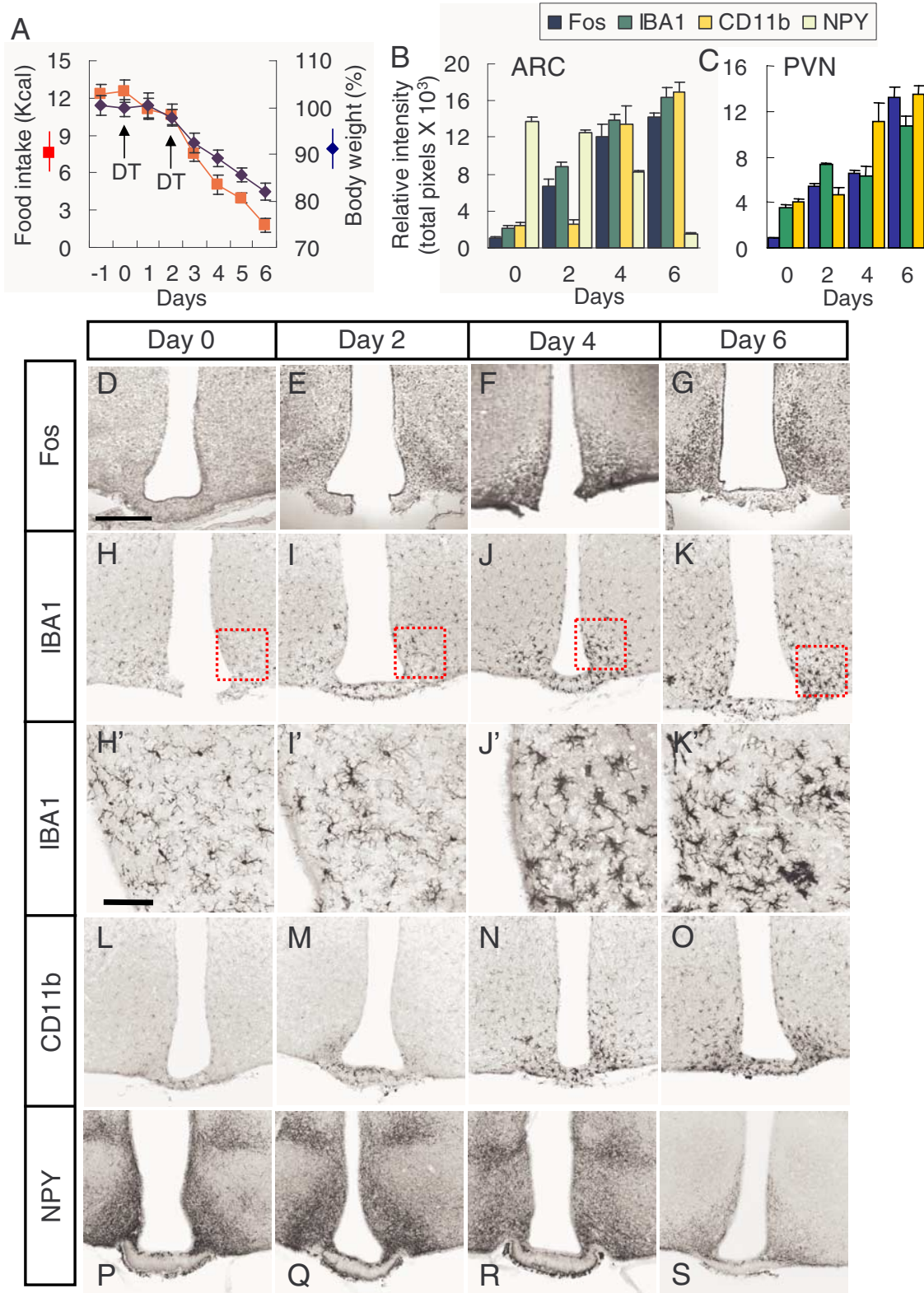

Figure 1. Kinetics of feeding response, Fos activation, gliosis, and NPY/AgRP cell death after injecting DT. $A$, Food intake and percentage of initial body weight of $\operatorname{Agrp}{ }^{D T R / D T R}$ mice $(n=6)$ after injections with $50 \mu \mathrm{g} / \mathrm{kg}$ DT on day 0 and day 2. Error bars represent \pm SEM. B, C, Quantified results for Fos, IBA1, CD11b, and NPY signals in ARC and PVN, respectively, are expressed as means of total pixels \pm SEM from at least 6 sections from 3 or 4 different mice in each group. $D-S$, Representative images of Fos $(\boldsymbol{D}-\boldsymbol{G})$, IBA1 $(\boldsymbol{H}-\boldsymbol{K}), \mathrm{CD} 11 \mathrm{~b}(\boldsymbol{L}-\mathbf{O})$, and NPY $(\boldsymbol{P}-\boldsymbol{S})$ immunocytochemistry in the ARC region of the hypothalamus after treating Agrp ${ }^{D T / D T R}$ mice with DT for $0,2,4$, or $6 \mathrm{~d}$. Scale bars: (in $\left.\boldsymbol{D}\right) \boldsymbol{D}-\boldsymbol{S}, 400 \mu \mathrm{m}$. $\boldsymbol{H}^{\prime}-\boldsymbol{K}^{\prime}$ are magnified views of the areas outlined in $\boldsymbol{H}-\boldsymbol{K}$, respectively; scale bar: (in $\boldsymbol{H}^{\prime}$ ) $\boldsymbol{H}^{\prime}-\boldsymbol{K}^{\prime}, 50 \mu \mathrm{m}$.

0.01). Chronic blockade of the MC4R signaling pathway by ectopic expression of agouti in $A^{y}$; $A g r p^{D T R /+}$ mice significantly attenuated Fos response in the PVN relative to $\operatorname{Agrp}^{D T R /+}$ mice (Fig. $4 E, E^{\prime}$ vs $\left.C, C^{\prime}\right)(p<0.01)$. Moreover, the data indicate that the induction of Fos was not caused by the stress of starvation or nonspecific DT toxicity, because PF and DT treatment in control mice had only small effects on Fos expression (Fig. $\left.4 A, A^{\prime}, B, B^{\prime}, D, D^{\prime}\right)$. These data indicate that neuronal activity in the PVN is greatly enhanced after removal of inhibitory AgRP input and that blockade of MC4R signaling ameliorated the excitability of the PVN.

Data consistency is illustrated in the duplicate figures (Fig. $4 A-E$ and $A^{\prime}-E^{\prime}$ ) and was verified by quantitative comparison of 

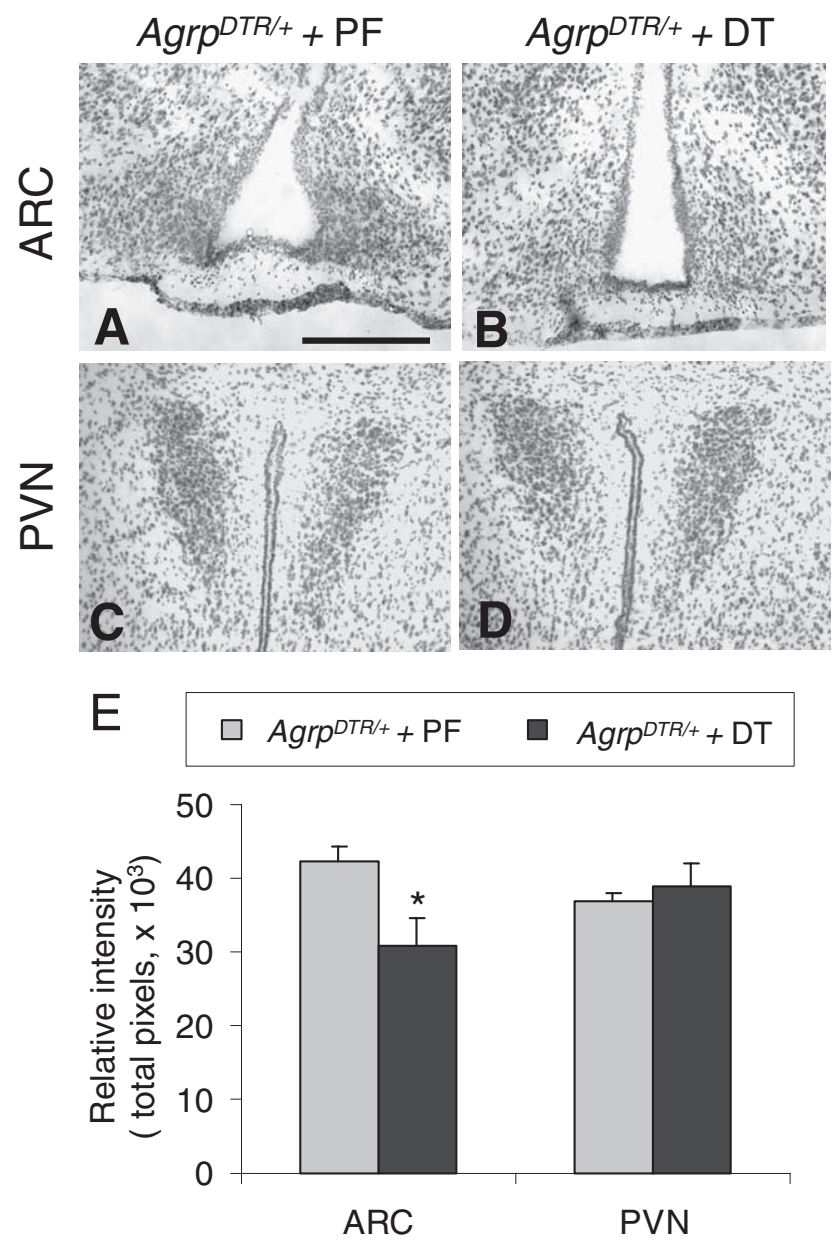

Figure 2. Nissl staining in ARC and PVN of pair-fed control and AgRP neuron-ablated mice. $A$, $\boldsymbol{B}$, Nissl staining results at the ARC of pair-fed naive $(\boldsymbol{A})$ and DT-treated $(\boldsymbol{B})$ Agrp $^{\text {DTR/+ }}{ }^{\text {mice. }} \boldsymbol{C}, \boldsymbol{D}$, Nissl staining results from the PVN of pair-fed naive $(\boldsymbol{C})$ and DT-treated $(\boldsymbol{D})$ Agrp ${ }^{D T R /+}$ mice. $\boldsymbol{E}$, Quantification of Nissl staining intensity is summarized as means of total pixels \pm SEM from 4 to 6 sections from 3 or 4 different mice in each group. ANOVA, ${ }^{*} p<0.01$. Scale bar: (in $\left.A\right) A-D$, $400 \mu \mathrm{m}$.

Fos mRNA level in anatomically matched brain sections of the cortex from control and experimental groups; this brain region is not known to be involved in regulation of energy balance (supplemental Fig. 1A-G, available at www.jneurosci.org as supplemental material). No statistical difference of signal intensity was found across control and neuron-ablated groups (supplemental Fig. $1 H$, available at www.jneurosci.org as supplemental material; ANOVA, $p>0.13$ ), suggesting that performing a direct comparison of Fos activity from mice of different genotypes is valid for identifying any difference at AgRP target areas.

We postulated that either loss of axon terminals caused by DT treatment of $A g r p^{D T R /+}$ mice or the ensuing excessive neuronal activation in postsynaptic targets of AgRP neurons could result in excitotoxicity and neuroinflammation, a cascade of events characterized by glial cell activation (Raivich et al., 1999). GFAP (an astrocyte marker) activation in the PVN of the DT-treated $A g r p^{D T R /+}$ mice and the $A y, A g r p^{D T R /+}$ mice relative to the four control groups is shown in Figure 4, F-K. Activation is revealed as an apparent increase in the immunostaining and change in morphology of the astrocytes (see Fig. $4 H^{\prime}, I^{\prime}$ for magnified views of the regions that are boxed in Fig. $4 H, I$, respectively). The activation of microglia was assessed by immunostaining with an anti- body against IBA1 in an adjacent set of sections from the six groups of mice (Fig. $4 L-Q$ and magnified in Fig. $4 N^{\prime}, O^{\prime}$ ). Quantitative analysis revealed numerous activated glial cells with compact, bushy processes in the PVN of DT-treated $\operatorname{Agrp}^{D T R /+}$ mice, whereas the majority of glial cells in pair-fed and DT-treated wild-type mice were resting, with fine ramifications of their processes (Fig. $4 H^{\prime}, I^{\prime}$ or $4 N^{\prime}, O^{\prime}$; quantified in Fig. $4 R$ ). Ablationinduced activation of both astrocytes and microglial cells was attenuated in DT-treated $A^{y} ; A g r p^{D T R /+}$ mice relative to Agrp ${ }^{D T R /+}$ mice (Fig. $4 R$ ), suggesting that glial cells in the PVN are sensitive to the antagonistic action of agouti on MC4Rexpressing neurons. These results indicate that glial cell markers provide an additional tool for assessing relevant AgRP target nuclei.

\section{Two distinct classes of AgRP targets are discerned by comparing the effects of AgRP ablation in $\operatorname{Agrp}^{D T R /+}$ and $\boldsymbol{A}^{y}$; $\operatorname{Agrp}^{D T R /+}$ mice}

Because our strategy recapitulated the functional relationship between AgRP neurons and target cells in the PVN, we proceeded to evaluate Fos expression in other brain regions that receive projections from AgRP neurons (Broberger et al., 1998; HaskellLuevano et al., 1999). To minimize the impact from the small variations underlying the automated process of in situ hybridization and image acquisition, we restricted our analysis to those brain regions in which there was $>50 \%$ increase in Fos mRNA in DT-treated $A g r p^{D T R /+}$ mice relative to pair-fed, DT-treated, wild-type mice. Six different regions fell within our screening criteria, including three hypothalamic nuclei [the ARC, the dorsal medial hypothalamus (DMH), and the medial preoptic area (MPO)] and three extrahypothalamic regions [the lateral septum (LS), the hippocampal dentate gyrus (DG), and the nucleus tractus solitarius (NTS)].

DT-treated Agrp ${ }^{D T R /+}$ mice showed significant Fos induction in all six regions $(\sim 7$-fold in the ARC, $\sim 2.5$-fold in the $\mathrm{DMH}$ and the MPO, $\sim 3$-fold in the LS, $\sim 2$-fold in the DG, $\sim 4$-fold in the NTS) compared with pair-fed, DT-treated, wild-type mice and pair-fed $A g r p^{D T R /+}$ mice (Fig. 5A-F; supplemental Figs. 2-7, available at www.jneurosci.org as supplemental material). However, comparing the Fos induction in DT-treated $A g r p^{D T R /+}$ mice and DT-treated $A^{y}$; $A g r p^{D T R /+}$ mice revealed different responses depending on the brain region examined. Fos expression was significantly reduced (55-85\%) in the ARC, DMH, MPO, and LS when the MC4R signaling was blocked by agouti (Fig. $5 A-D$; supplemental Figs. 2-5, available at www.jneurosci.org as supplemental material; $p<0.01$ ). In contrast, the intensity of the Fos signal was the same in the DG and the NTS when comparing the effect of DT in mice with or without $A^{y}$ gene (Fig. $5 E, F$; supplemental Figs. 6,7, available at www.jneurosci.org as supplemental material; $p>0.59$ ). These results suggest that POMC neurons are opposed by AgRP signaling in the ARC, DMH, MPO, and LS, as they are in the PVN. The observation that chronic blockade of MC4R by agouti elicited virtually no impact on neuron hyperactivity in the DG and the NTS suggests that melanocortin signaling in those regions does not contribute to neuronal activation.

We also examined the response of glial cells in these target brain regions. The data reveal that astrocytes and microglia were activated to various extents in the ARC, DMH, MPO, and LS of DT-treated Agrp ${ }^{D T R /+}$ mice compared with WT and pair-fed control groups, implying that ablation of AgRP neurons caused significant neuron activation and/or damage in these downstream areas (Fig. 5A-D; supplemental Figs. 8-15, available at www.jneurosci.org as supplemental material). However, differ- 
ing from the attenuated glial response shown in the PVN of DT-treated $A^{y}$; Agrp ${ }^{D T R /+}$ mice, the astrocytes and microglia in the ARC, DMH, MPO, and LS of the $A^{y} ; A g r p^{D T R /+}$ mice remained abnormally active, except for a reduced IBA1 immunoreactivity in the DMH. DT treatment elicited comparable glial reactivity in the DG of wild-type, $\operatorname{Agr} p^{D T R /+}$, and $A^{y}$; Agrp ${ }^{D T R /+}$ mice, which may be attributable to nonspecific, DT-mediated toxicity; nevertheless, astrocytes, but not microglia, in the NTS exhibited more robust reactivity in neuron-ablated mice compared with DT-treated wild-type mice (Fig. 5E,F; supplemental Figs. 16-19, available at www.jneurosci.org as supplemental material).

\section{Some postsynaptic targets of AgRP neurons manifest neither Fos activation nor gliosis}

Whereas most brain regions that are established targets of AgRP neurons revealed robust activation of Fos gene expression and glia, others such as the bed nucleus of the stria terminalis (BST), the ventral tegmental area (VTA), and the paranigral nucleus (PN) did not. Examples of brain regions that receive extensive innervation from AgRP neurons but did not show any significant Fos induction or activation of astrocytes or microglia are shown in Figure 6. The innervation of these regions by AgRP neurons, based on immunohistochemistry by Broberger et al. (1998), are as extensive as in other regions (e.g., the MPO and LS) in which Fos was robustly induced. These results indicate that loss of AgRP axons does not invariably lead to Fos activation or gliosis.

\section{Discussion}

Mice with targeted ablation of hypothalamic AgRP-expressing neurons provided a unique opportunity to study the activation of neural circuits that presumably mediate the starvation phenotype. We found that ablation of AgRP neurons leads to a dramatic activation of Fos in most, but not all, known targets of POMC and AgRP neurons. Activated microglia and astrocytes were also detected in most regions displaying elevated Fos expression. Chronic blockade of melanocortin signaling by ectopic expression of agouti attenuated Fos expression in all brain regions except for the DG and the NTS, but did not prevent starvation (Wu et al., 2008). We hypothesize that the dysregulation of neuronal signaling as indicated by activation of Fos expression mediates the starvation phenotype.

A relatively complete profile of AgRP- and POMCimmunoreactive fibers projected from the ARC has been characterized in rodents (Jacobowitz and O'Donohue, 1978; Watson et al., 1978; Nilaver et al., 1979; Broberger et al., 1998; HaskellLuevano et al., 1999). However, the functional significance of the overlap in POMC- and AgRP-positive fibers in target areas has not been examined. We used the semiautomated, whole-brain, in situ hybridization approach to gain functional information about the relative importance of various signaling pathways. Fos expression throughout the brain was examined, with special attention to the sites that receive projections from AgRP neurons. We sus- pect that activation of Fos reflects unbalanced excitatory and inhibitory inputs to the Fos-expressing cells. Most of the excitatory input presumably comes from glutamatergic afferents, along with activation by various $\mathrm{G}_{\alpha \mathrm{s}^{-}}$and $\mathrm{G}_{\alpha \mathrm{q}^{-}}$-coupled receptors, whereas most of the inhibitory inputs come from GABAergic activation of $\mathrm{GABA}_{\mathrm{A}}$ receptors and activation of $\mathrm{G}_{\alpha \mathrm{i}^{-}}$and $\mathrm{G}_{\alpha \mathrm{o}^{-}}$ coupled receptors. Thus, ablation of AgRP neurons is predicted to remove several inhibitory inputs to postsynaptic neurons, resulting in unopposed excitation and consequent induction of Fos gene expression. Most postsynaptic neurons probably receive excitatory inputs in addition to those from POMC neurons. Thus, whether Fos is activated or not and whether it is affected by blockade of melanocortin signaling would likely depend on the relative strengths of the various inputs.

We present evidence indicating that only some of the established AgRP-immunoreactive sites displayed elevated Fos induction after AgRP neuron ablation, including the ARC, PVN, DMH, MPO, and LS, whereas other areas did not manifest enhanced Fos expression. AgRP target areas were evaluated based on screening results, with statistical difference between foodrestricted animals and neuron-ablated animals. Brain areas that had Fos expression below an appreciable level or with insignificant change relative to food-restricted animals were excluded from our analysis. For example, the paraventricular nucleus of the thalamus receives sparse innervations of AgRP fibers, yet it displayed a comparable, prominent Fos expression in foodrestricted control mice and DT-treated $\operatorname{Agrp}^{D T R /+}$ mice (data not shown). Other regions that are clearly innervated by AgRP fibers, such as the red nucleus, the VTA, and the periaqueductal gray, showed minimal or no Fos activity (Fig. 6) (data not shown). Several possibilities may underlie that lack of Fos induction in some brain regions after loss of AgRP neuron innervation. First, inhibition from AgRP neurons may be a small fraction of total inhibitory inputs. Second, some targets of AgRP neurons may not 


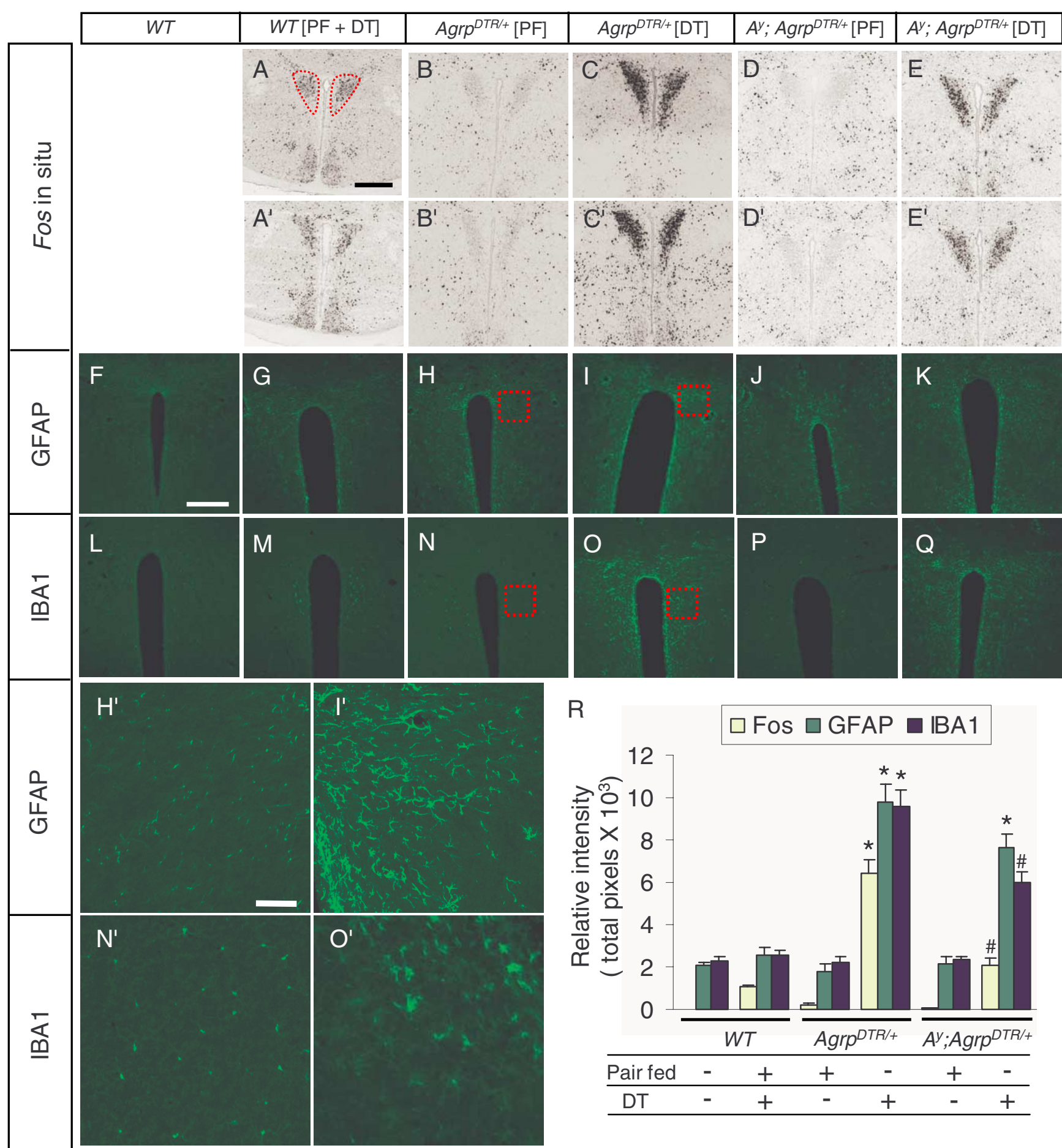

Figure 4. Blockade of MC4R signaling counteracts Fos induction and ameliorates the hypersensitivity of glial cells in the PVN of AgRP-ablated mice. Two representative pictures of Fos in situ hybridization in the PVN (area denoted by dotted lines in $\boldsymbol{A}$ ) from WT mice, Agrp ${ }^{D T R /+}$ mice, or $A^{y} ; A g r p^{D T R /+}$ mice that were pair fed and either treated with DT or not. $\boldsymbol{A}, \boldsymbol{A}^{\prime}$, WT mice pair fed and

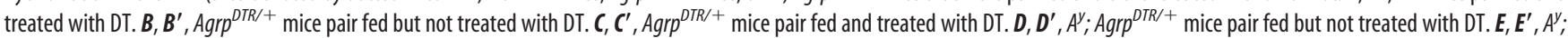
Agrp ${ }^{D T R /+}$ mice pair fed and treated with DT. There was no appreciable Fos expression in the untreated wild-type mice (data not shown). $\boldsymbol{F}-\boldsymbol{K}$, Representative images of GFAP (astrocyte marker) immunocytochemistry in the PVN of WT mice and the 6 treatment groups. $L-Q$, Representative images of IB1A (microglial marker) immunocytochemistry in the PVN of WT mice and the 6 treatment groups. Scale bars: (in $\boldsymbol{A}, \boldsymbol{F}) \boldsymbol{A}-\boldsymbol{Q}, 400 \mu \mathrm{m} . \boldsymbol{H}^{\prime}, \boldsymbol{I}^{\prime}, \boldsymbol{N}^{\prime}$, and $\boldsymbol{O}^{\prime}$ are magnified views of the areas outlined in $\boldsymbol{H}, \boldsymbol{I}, \boldsymbol{N}$, and $\boldsymbol{O}$, respectively; scale bar: (in $\boldsymbol{H}^{\prime}$ ) $\boldsymbol{H}^{\prime}-\boldsymbol{O}^{\prime}, 50 \mu \mathrm{m} . \boldsymbol{R}, \mathbf{Q}$ uantified results for Fos, GFAP, and IBA1 signals in PVN from 4 mice are expressed as means of total pixels \pm SEM from at least 6 sections from 3 or 4 different mice in each group. Statistical comparisons were made by ANOVA: ${ }^{*} p<0.05$ between the $A g r p^{D T R /+}$ or $A^{y} ;$ Agrp $^{\text {DTR/+ }}$ group and any of the controls; ${ }^{\#} p<0.05$ between similar measurements in the Agrp ${ }^{D T R /+}$ and $A^{y} ; A g r p^{D T R /+}$ groups.

receive strong excitatory inputs. Third, induction of Fos requires multiple cellular signals (for example, calcium- and cAMPmediated signals), and some of these signals may be absent. Fourth, we only examined Fos expression thoroughly at day 6; thus, some early changes may have resolved by then. Therefore, the AgRP-projection areas that we studied here represent a subset of those that could be important in mediating starvation.

Six days after DT treatment, there were few remnants of AgRP 
neurons in the ARC as assessed by in situ hybridization or immunohistochemistry. Nearly all of the neighboring POMC neurons expressed Fos mRNA, as expected, but many other unidentified neurons in the ARC were also Fos positive. We observed strong glial cell activation in the ARC $6 \mathrm{~d}$ after commencing DT treatment. Activated microglia and astrocytes underwent dramatic morphological changes including enlargement of the cell soma and thickening of proximal process (Ladeby et al., 2005). Interestingly, the activation of Fos and the microglial marker IBA1 was apparent in the ARC by day 2, before any loss of neurons or an effect on feeding. DT acts by inhibiting protein synthesis (Collier, 1975), so we presume that AgRP neuron function is initially impaired and progresses to cell death a few days later. The activation of Fos presumably reflects loss of inhibitory inputs onto POMC and other local neurons from impaired AgRP neurons, although the microglial activation may represent responses to distress signals from either the impaired AgRP neurons or overly excited postsynaptic cells. By day 4, the CD11b microglial marker became prominent, which coincides with the time when AgRP neuron markers began to disappear; hence, CD11b may reflect a more advanced stage of microglial activation, perhaps associated with phagocytosis of dying cells.

Glial cell activation in postsynaptic targets of AgRP neurons was also robust and was associated with Fos induction in the DMH, PVN, MPO, and LS. Such glial cell activation could reflect responses to axonal degeneration, but glutamatemediated activation of astrocytes is also possible (Raivich et al., 1999; Garden and Möller, 2006; Hanisch and Kettenmann, 2007). Astrocytes normally express glutamate receptors, whereas microglial cells only express glutamate receptors after they become activated; both cell types can be killed by glutamate (Matute et al., 2006), and gliosis can precede neuronal degeneration in some situations (Kielar et al., 2007). The parallel amelioration of glial and Fos activation by agouti expression in the PVN, under conditions in which axonal degeneration was the same, provides an example for which something other than axon degeneration, perhaps glutamate, modulates glial cell activation. In some brain regions, AgRP neuron terminals degenerate, but there was no activation of Fos or glial markers. This observation suggests that axonal degeneration is insufficient to activate microglia and favors an excitotoxic interpretation. The observations that glial cell activation occurs only in brain regions that are direct targets of AgRP neurons indicate that activation is not propagated to downstream neurons. It is unlikely that gliosis and subsequent release of cytokines is directly responsible for starvation in this model, because ablation of POMC neurons, which reside in and project to virtually all of the same brain regions as AgRP neurons, does not result in starvation (Gropp et al., 2005). Quantitative analysis of neuronal loss in target areas based on Nissl staining did not reveal evidence of pyknotic nuclei or reduced neuronal density in any of the brain regions that received the highest glial cell activation scores, except for the ARC, in which there was obvious loss of neurons. Thus, we tentatively suggest that glial cell activation in target areas reflects a neuroprotective role of these cells rather than contributing to neurotoxicity.

Two brain regions (the DG and NTS) showed Fos activation after DT treatment that was not attenuated in the $A^{y}$ genetic background. In both of these regions the glial cell activation was observed in all groups treated with DT, even in wild-type mice. Thus, glial cell activation in these brain regions could reflect enhanced sensitivity to DT. Because AgRP-immunoreactive fibers have not been reported in the DG (Haskell-Luevano et al., 1999) 


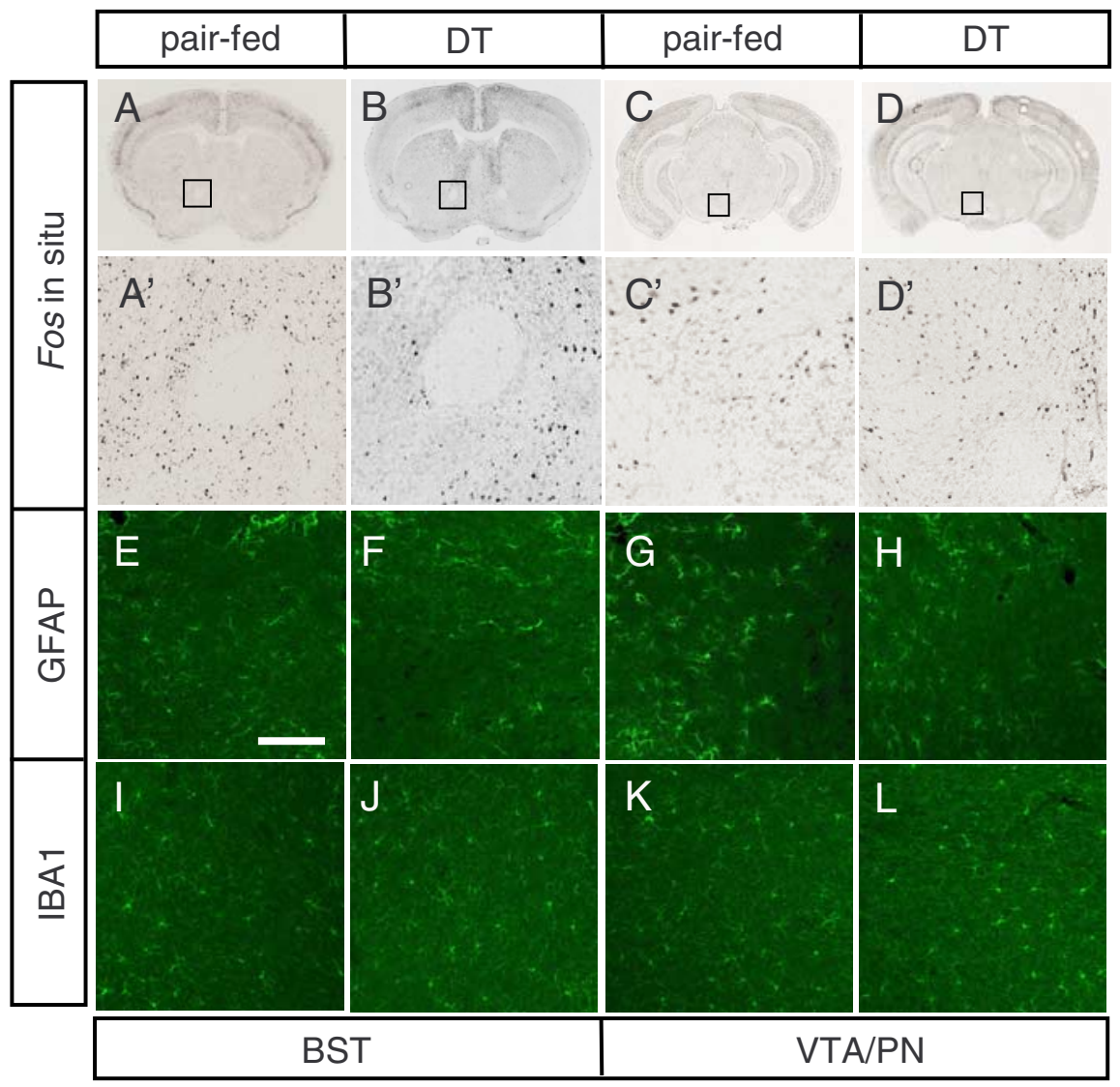

Figure 6. Some postsynaptic targets of AgRP neurons show neither Fos activation nor gliosis. $A-L$, Representative pictures of Fos in situ hybridization $\left(\boldsymbol{A}-\boldsymbol{D}, \boldsymbol{A}^{\prime}-\boldsymbol{D}^{\prime}\right)$ and glial cell activation as shown by GFAP $(\boldsymbol{E}-\boldsymbol{H})$ and IBA1 $(\boldsymbol{I}-\boldsymbol{L})$ immunostaining in the BST, the VTA, and the PN. $A, C, E, G, I, K$, Agrp $^{\text {DTR/++}}$ mice that were pair fed to comparable weight loss. $\boldsymbol{B}, \boldsymbol{D}, \boldsymbol{F}, \boldsymbol{H}, \boldsymbol{J}, \boldsymbol{L}, \mathrm{Agrp}^{\mathrm{DTR} /+}$ mice that were treated with DT. $\boldsymbol{A}^{\prime}-\boldsymbol{D}^{\prime}$, Magnified views of the areas outlined in $\boldsymbol{A}-\boldsymbol{D}$, respectively. Scale bar (in $\boldsymbol{E}$ ): $\boldsymbol{E}-\boldsymbol{L}, 50 \mu \mathrm{m}$. direct AgRP projections to the NTS (Broberger et al., 1998) or is an indirect consequence of dysregulation in other brain regions that send projections to the NTS.

\section{References}

Badman MK, Flier JS (2005) The gut and energy balance: visceral allies in the obesity wars. Science 307:1909-1914.

Balthasar N, Dalgaard LT, Lee CE, Yu J, Funahashi H, Williams T, Ferreira M, Tang V, McGovern RA, Kenny CD, Christiansen LM, Edelstein E, Choi B, Boss O, Aschkenasi C, Zhang CY, Mountjoy K, Kishi T, Elmquist JK, Lowell BB (2005) Divergence of melanocortin pathways in the control of food intake and energy expenditure. Cell 123:493-505.

Broberger C, Johansen J, Johansson C, Schalling M, Hökfelt T (1998) The neuropeptide Y/agouti gene-related protein (AGRP) brain circuitry in normal, anorectic, and monosodium glutamate-treated mice. Proc Natl Acad Sci U S A 95:15043-15048.

Cole TB, Robbins CA, Wenzel HJ, Schwartzkroin PA, Palmiter RD (2000) Seizures and neuronal damage in mice lacking vesicular zinc. Epilepsy Res 39:153-169.

Collier RJ (1975) Diphtheria toxin: mode of action and structure. Bacteriol Rev 39:54-85.

Cone RD (2005) Anatomy and regulation of the central melanocortin system. Nat Neurosci 8:571-578.

Cowley MA, Smart JL, Rubinstein M, Cerdán MG, Diano S, Horvath TL, Cone RD, Low MJ (2001) Leptin activates anorexigenic POMC neurons through a neural network in the arcuate nucleus. Nature 411:480-484.

Fields RD, Stevens-Graham B (2002) New insights into neuron-glia communication. Science 298:556-562.

activation of Fos there probably reflects activation from some other brain region as a consequence of AgRP neuron ablation. Excitotoxicity in the hippocampus in response to seizures results in DG neuron cell death and activation of Npy gene expression (Palmiter et al., 1998;Vezzani et al., 1999; Cole et al., 2000), but we did not observe any significant cell death or changes in Npy mRNA among control and AgRP-ablated experimental groups (data not shown), suggesting that the activation was mild relative to that which occurs during seizures. Because the DG has never been implicated in regulation of feeding behavior and it is not a direct target of AgRP neurons, we discount the significance of Fos activation there.

The other brain region in which loss of MC4R signaling did not affect Fos induction was the NTS; however, the identity of the Fos-positive cells in the NTS is currently unknown. The NTS is traditionally perceived as a center for detection and transduction of satiety signals from vagal afferents, and gut peptides, like cholecystokinin (Badman and Flier, 2005). The NTS also responds to glucose, leptin, melanocortin, and urocortin (Grill and Kaplan, 2002). There is general agreement that activation of caudal brainstem is necessary for feeding (Grill, 2006). A reciprocal crosstalk between the NTS and hypothalamic cell groups including the AgRP and POMC neurons may underlie the NTS mediation of feeding activity (Cone, 2005). We hypothesize that dysregulation within the NTS mediates the inhibition of food intake measured by intraoral infusion of food directly into the mouth of AgRP neuron-ablated mice (Wu et al., 2008). However, it is not established whether activation of Fos in the NTS is caused by a loss of
Garden GA, Möller T (2006) Microglia biology in health and disease. J Neuroimmune Pharmacol 1:127-137.

Grill HJ (2006) Distributed neural control of energy balance: contributions from hindbrain and hypothalamus. Obesity (Silver Spring) 14 [Suppl 5]:216S-221S.

Grill HJ, Kaplan JM (2002) The neuroanatomical axis for control of energy balance. Front Neuroendocrinol 23:2-40.

Gropp E, Shanabrough M, Borok E, Xu AW, Janoschek R, Buch T, Plum L, Balthasar N, Hampel B, Waisman A, Barsh GS, Horvath TL, Brüning JC (2005) Agouti-related peptide-expressing neurons are mandatory for feeding. Nat Neurosci 8:1289-1291.

Hanisch UK, Kettenmann H (2007) Microglia: active sensor and versatile effector cells in the normal and pathologic brain. Nat Neurosci 10:1387-1394.

Hara J, Beuckmann CT, Nambu T, Willie JT, Chemelli RM, Sinton CM, Sugiyama F, Yagami K, Goto K, Yanagisawa M, Sakurai T (2001) Genetic ablation of orexin neurons in mice results in narcolepsy, hypophagia, and obesity. Neuron 30:345-354.

Hara MR, Snyder SH (2007) Cell signaling and neuronal death. Annu Rev Pharmacol Toxicol 47:117-141.

Haskell-Luevano C, Chen P, Li C, Chang K, Smith MS, Cameron JL, Cone RD (1999) Characterization of the neuroanatomical distribution of agoutirelated protein immunoreactivity in the rhesus monkey and the rat. Endocrinology 140:1408-1415.

Jacobowitz DM, O’Donohue TL (1978) alpha-Melanocyte stimulating hormone: immunohistochemical identification and mapping in neurons of rat brain. Proc Natl Acad Sci U S A 75:6300-6304.

Kielar C, Maddox L, Bible E, Pontikis CC, Macauley SL, Griffey MA, Wong M, Sands MS, Cooper JD (2007) Successive neuron loss in the thalamus and cortex in a mouse model of infantile neuronal ceroid lipofuscinosis. Neurobiol Dis 25:150-162.

Kublaoui BM, Holder JL Jr, Tolson KP, Gemelli T, Zinn AR (2006) SIM1 
overexpression partially rescues agouti yellow and diet-induced obesity by normalizing food intake. Endocrinology 147:4542-4549.

Ladeby R, Wirenfeldt M, Garcia-Ovejero D, Fenger C, Dissing-Olesen L, Dalmau I, Finsen B (2005) Microglial cell population dynamics in the injured adult central nervous system. Brain Res Brain Res Rev 48:196-206.

Lein ES, Hawrylycz MJ, Ao N, Ayres M, Bensinger A, Bernard A, Boe AF, Boguski MS, Brockway KS, Byrnes EJ, Chen L, Chen L, Chen TM, Chin MC, Chong J, Crook BE, Czaplinska A, Dang CN, Datta S, Dee NR, et al. (2007) Genome-wide atlas of gene expression in the adult mouse brain. Nature 445:168-176.

Luquet S, Perez FA, Hnasko TS, Palmiter RD (2005) NPY/AgRP neurons are essential for feeding in adult mice but can be ablated in neonates. Science 310:683-685.

Luquet S, Phillips CT, Palmiter RD (2007) NPY/AgRP neurons are not essential for feeding responses to glucoprivation. Peptides 28:214-225.

Marsh DJ, Hollopeter G, Kafer KE, Palmiter RD (1998) Role of the Y5 neuropeptide Y receptor in feeding and obesity. Nat Med 4:718-721.

Matute C, Domercq M, Sánchez-Gómez MV (2006) Glutamate-mediated glial injury: mechanisms and clinical importance. Glia 53:212-224.

Michaud EJ, Bultman SJ, Stubbs LJ, Woychik RP (1993) The embryonic lethality of homozygous lethal yellow mice (Ay/Ay) is associated with the disruption of a novel RNA-binding protein. Genes Dev 7:1203-1213.

Nilaver G, Zimmerman EA, Defendini R, Liotta AS, Krieger DT, Brownstein MJ (1979) Adrenocorticotropin and beta-lipotropin in the hypothala- mus. Localization in the same arcuate neurons by sequential immunocytochemical procedures. J Cell Biol 81:50-58.

Paxinos G, Frank KB (2001) The mouse brain in stereotaxic coordinates. San Diego: Academic.

Pedrazzini T, Seydoux J, Künstner P, Aubert JF, Grouzmann E, Beermann F, Brunner HR (1998) Cardiovascular response, feeding behavior and locomotor activity in mice lacking the NPY Y1 receptor. Nat Med 4:722-726.

Phillips CT, Palmiter RD (2008) Role of agouti-related protein-expressing neurons in lactation. Endocrinology 149:544-550.

Raivich G, Bohatschek M, Kloss CU, Werner A, Jones LL, Kreutzberg GW (1999) Neuroglial activation repertoire in the injured brain: graded response, molecular mechanisms and cues to physiological function. Brain Res Brain Res Rev 30:77-105.

Vezzani A, Sperk G, Colmers WF (1999) Neuropeptide Y: emerging evidence for a functional role in seizure modulation. Trends Neurosci 22:25-30.

Watson SJ, Akil H, Richard CW 3rd, Barchas JD (1978) Evidence for two separate opiate peptide neuronal systems. Nature 275:226-228.

Wu Q, Howell MP, Cowley MA, Palmiter RD (2008) Starvation after AgRP neuron ablation is independent of melanocortin signaling. Proc Natl Acad Sci U S A 105:2687-2692.

Yang C, Gagnon D, Vachon P, Tremblay A, Levy E, Massie B, Michaud JL (2006) Adenoviral-mediated modulation of Sim1 expression in the paraventricular nucleus affects food intake. J Neurosci 26:7116-7120. 